\title{
NEW CULTIVARS
}

Keywords: cultivar: Dionaea muscipula 'Blanche Hermine', Sarracenia 'Jeremy', Sarracenia 'Illuminated Hut', Sarracenia 'Pomegranate', Sarracenia 'Saxapahaw'.

\section{Dionaea muscipula 'Blanche Hermine'}

Submitted: 20 J anuary 2012

Dionaea muscipula 'Blanche Hermine' is a white sport from a variegated Venus Flytrap that I found in M ay 2008 at the Carniflora open day. In September, I was able to take a bulb cutting. The mother plant died from frost during winter 2008/2009.

A small very white plant started to grow from this bulb cutting. I thought that this white plant would die once the reserves of the cutting were exhausted. To see this plant resuming growth in spring 2009 was quite a big surprise for me! The plant must certainly still have had some chlorophyll traces in its leaf, hardly visible in the white leaf tissue (see Fig. 1). Dionaea muscipula 'Blanche Hermine' is quite a slow grower because of the deficiency of chlorophyll, but it is possible to do leaf and bulb cuttings to maintain the unique features of this plant.

Blanche Hermine is a very good white beer produce in B ritain, where the plant was born. It's also a small animal of the family of M ustélidae (M ustela ermina) which one sees everywhere in Europe. In winter, its fur becomes very white except the end of the tail which remains black. When a leaf starts to die the trap becomes black; the contrast with the white remainder of the petiole makes me think of the winter dress of M ustela ermina.
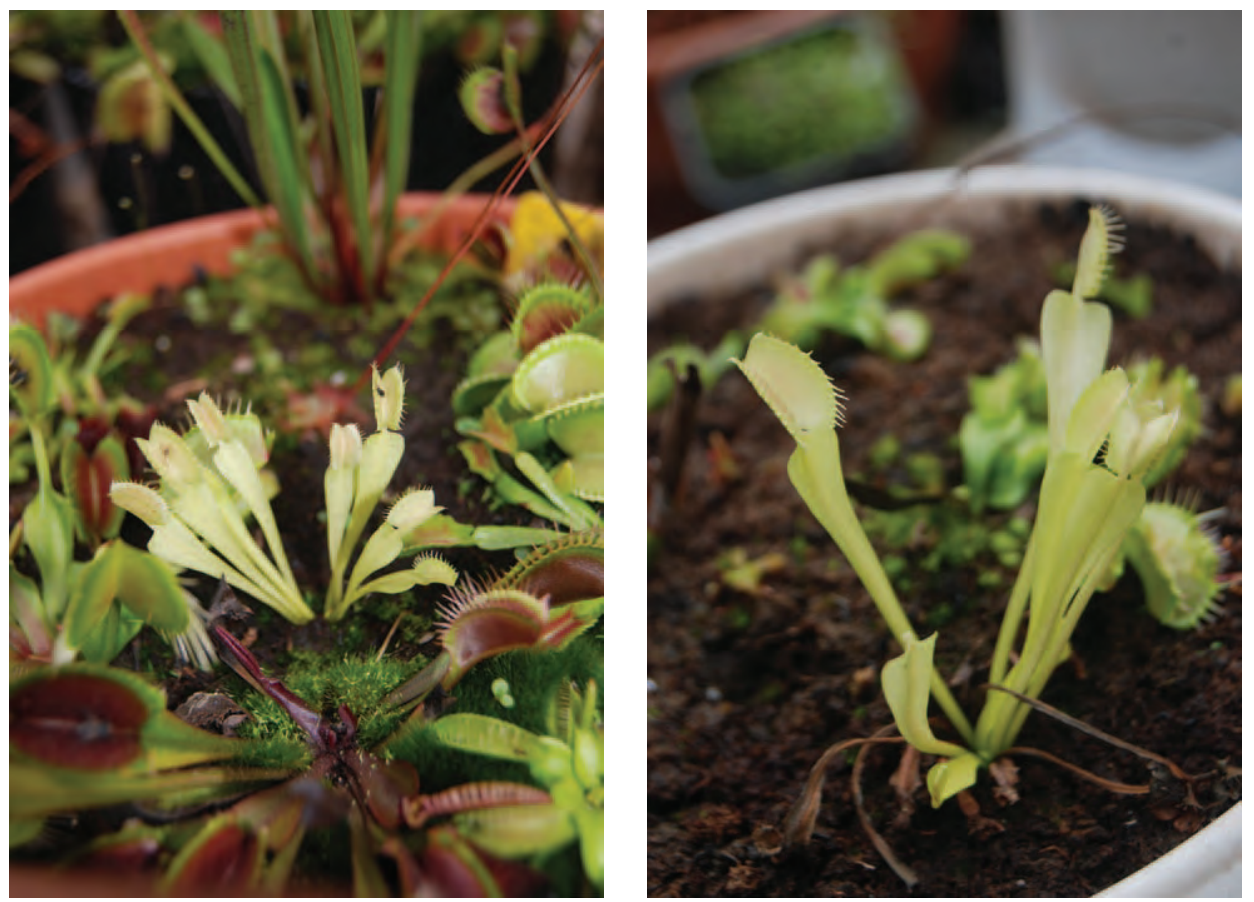

Figure 1: Dionaea muscipula 'Blanche Hermine' - a white Venus Flytrap.

- Guillaume BiLY • 10 allée des pétrels•56520 Guidel •France • gbily2003@yahoo.fr 
Submitted: 11 A pril 2012

Sarracenia 'J eremy' was a cross made by pollination of Sarracenia leucophylla and Sarracenia $\times$ mitchelliana (S. purpurea $\times$ S. leucophylla) in 1999. I sowed the seed and selected one seedling which after 5 years revealed red flowers like the parents and the pitchers resemble a blend of the colorful venation of Sarracenia leucophylla with more upright and narrower pitchers than exhibited by Sarracenia $\times$ mitchelliana. The epithet refers to my son's name. The pitchers grow to a height of 40 to $45 \mathrm{~cm}$ with a lid that is wavy with a rich, red venation under it (see Fig. 2). Right now the rhizome is divided and each one has a flower spike. The plant grows quite vigorously and the best pitchers grow in the fall like the $S$. leucophylla parent which last a long time before going dormant.
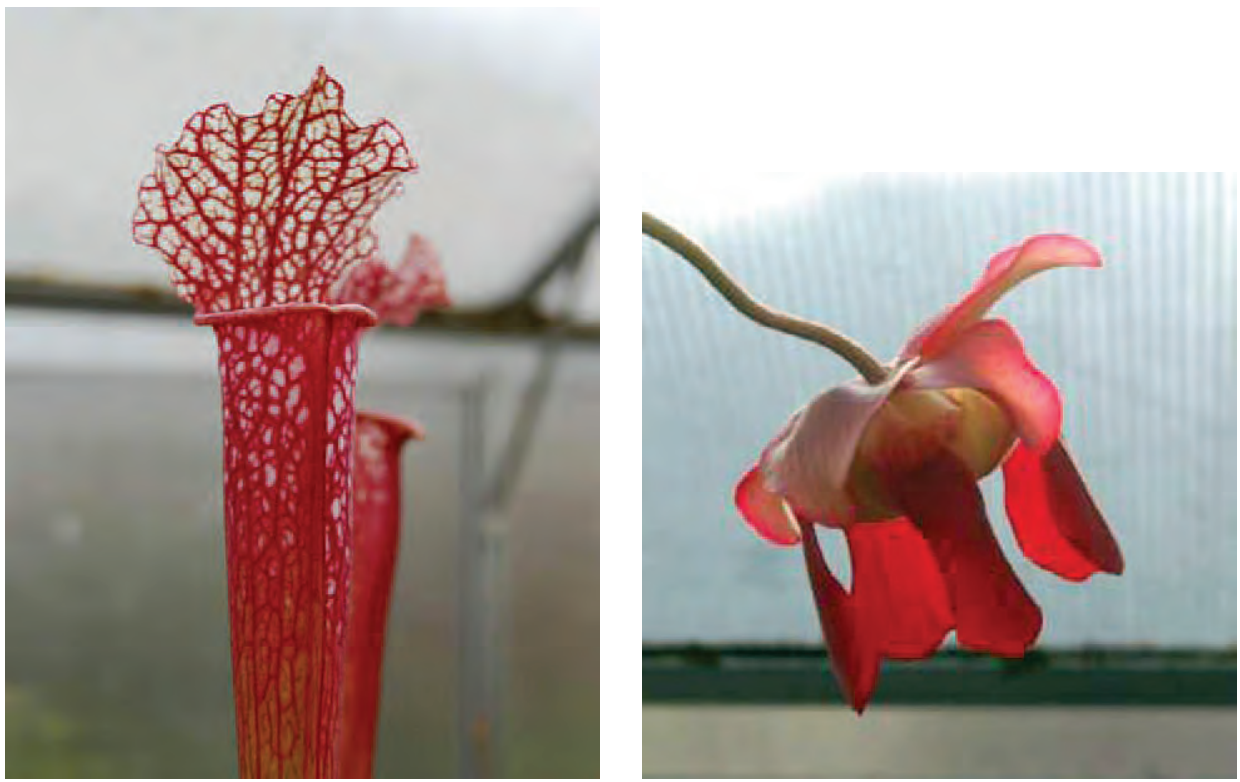

Figure 2: Sarracenia 'Jeremy' pitcher and flower.

- LARRY LOGOTETA • M anteca • California 95336•USA • hotrods240@yahoo.com

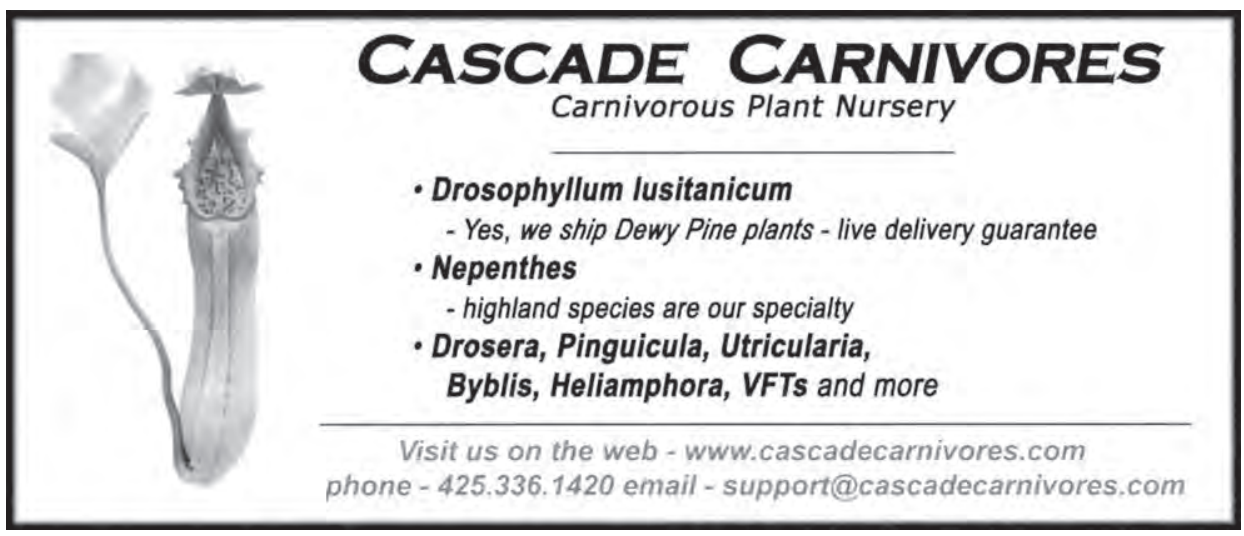


I developed Sarracenia 'Illuminated Hut' by transferring the pollen from a tall, vigorous S. leucophylla onto the stigma of a (S. purpurea) $\times(S . \times$ courtii) that has short pitchers and appear pink to light purple in full sunlight. B oth parent plants have a dark red petal color. The pollination was made on 22 J anuary 2008. Seeds began sprouting on 11 J une. The plant is just over three years old and the adult pitchers have so far attained a height of $38 \mathrm{~cm}$.

Unlike many S. purpurea or S. psittacina hybrids, this particular plant has characteristics very similar to S. leucophylla due to the ruffled lid, fenestrations on the lid, and its tall habit. In contrast to $S$. leucophylla, the lid and top section of the pitcher takes on a bright pink coloration, the pitchers are shorter than the parent S. leucophylla, and have a sturdy habit. Furthermore, the lid is slightly opened at the top, allowing for the opportunity of a small amount of rainwater to enter the pitchers (see Fig. 3). This plant has not flowered so far, although it is expected to in a year's time.

A very strong plant, S. 'Illuminated Hut' is resistant to short periods of heavy rain, maintaining its upright growth. The attractive color of the lid and mouth region of the pitcher attracts flying insects. The lid's shape takes on the roof of a hut, hence the term "Hut", and the fenestrations on the lid, hence the term "Illuminated". I coined this name in O ctober 2011. This plant needs to be propagated by rhizome divisions to maintain its characteristics.

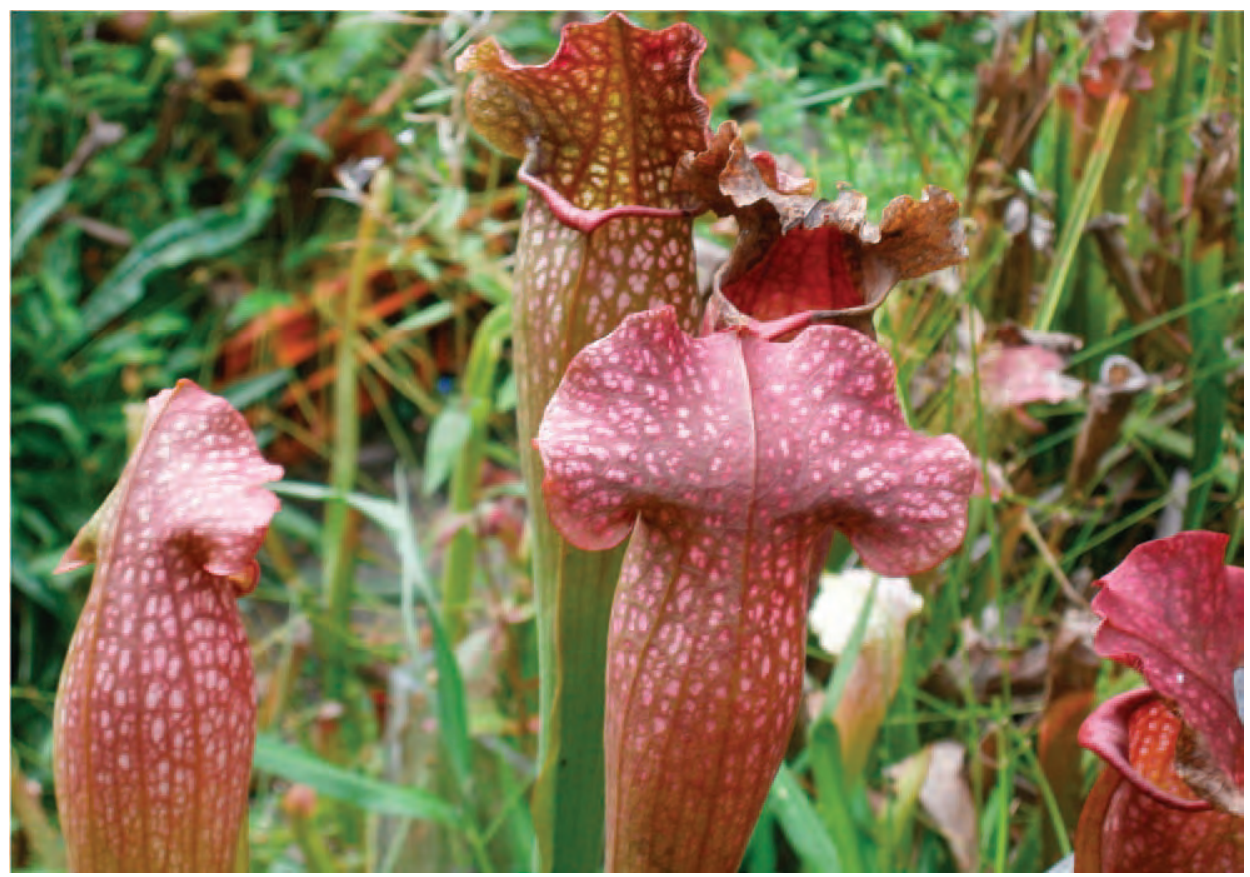

Figure 3: Sarracenia 'Illuminated Hut'. Photo taken January 2011.

-Steve Amoroso •A ustralia • steve.1600@yahoo.com 
I developed Sarracenia 'Pomegranate' by transferring the pollen from a $(\mathrm{S} . \times$ willisii $) \times(\mathrm{S} . \times$ mitchelliana) to the stigma of a S. oreophila. The pollination occurred on 20 ctober 2006 and the resultant plant is currently in its $4^{\text {th }}$ year of growth. The flower scape had snapped off of the seed capsule plant early in J anuary 2007 and I dried the seed capsule in an open dry plastic container outdoors in a shaded area. On 13 J anuary, inspection of the flower pod revealed two mature seeds that I sowed on pure peat moss on the same day. By July, only one of the seeds had sprouted.

The pollen parent has short, very thin dark red pitchers, whereas the ovary parent is a pure green form of S. oreophila that produces tall pitchers $60 \mathrm{~cm}$ in height. The pollen parent produces red petals reminiscent of $\mathrm{S}$. purpurea, whereas the ovary parent produces yellow petals. The resultant hybrid has flowered for two years in a row, the first time in spring 2010 and a second time in 2011. Petals are a light red color. No seeds have been produced to date. This plant is quite vigorous, producing new divisions relatively fast. Pitchers are tall, reaching up to $40 \mathrm{~cm}$ and are generally green with a red tint on the lid and the top section behind the pitcher. The lid has a unique appearance, taking on almost an inverted spoon shape and is pointed (see Fig. 4). The external surface of the pitcher is green in color, whereas the internal surface is heavily veined. I coined the name "pomegranate" on 29 February 2012 as the red coloration on the lid is reminiscent to the surface of a pomegranate fruit. This plant should be propagated by divisions to maintain its characteristics.
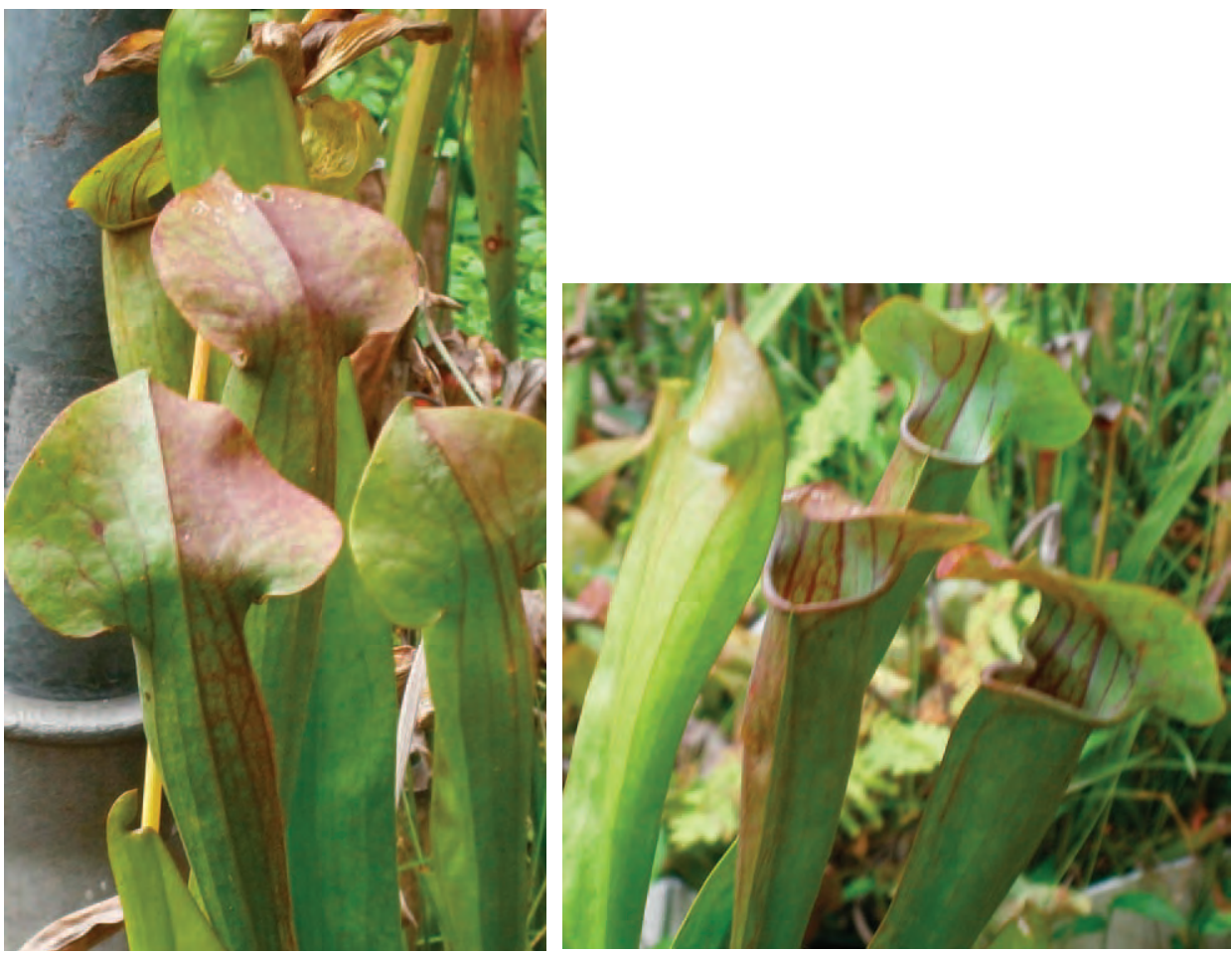

Figure 4: Sarracenia 'Pomegranate'.

-Steve Amoroso •A ustralia • steve.1600@yahoo.com 
A specimen of the original plant was sent to me by J ames Stoner in the winter of 2009. Two years passed and this plant grew to a stunning size in the spring, summer, and fall of 2010 and 2011. The plant exhibits outstanding colors and size and spreads vigorously in our gardens. I quickly contacted J ames regarding the background of this plant and began researching it myself. Despite James' and my attempts, no background information was found. I believe the plant was mislabeled in the past so very little history on the plant's origin exists.

In the spring the plant sends up reddish pitchers tipped with $2-4 \mathrm{~cm}$ of blended bright yellow coloration. When the pitchers open, their insides are filled with pale yellow with distinct streaks of red veining patterns throughout the underside of the hood and their outer surfaces are speckled with pink reticulations (see Fig. 5 left). Once the plant is established for more than one year, tall pitchers up to $70 \mathrm{~cm}$ begin to darken throughout the summer season, the pitchers transition to burgundy, and peristomes change from a deep burgundy to ruddy brown in bright sun (see Fig. 5 right). The peristome widths range from 6 to $8 \mathrm{~cm}$ wide. Pitchers may reach sizes larger than recorded measurements if grown in bright conditions and left for repeated seasons without dividing. In fall this process repeats itself. The parental background of this plant is a mystery. It appears that this plant has ancestry from Sarracenia flava var. atropurpurea and S. leucophylla. The flowers are dark red, similar to S. leucophylla with pale blotches of yellow on each petal.

Sarracenia 'Saxapahaw' is named after a Native A merican tribe of N orth Carolina's H aw River, whose history is also a mystery. Saxapahaw is now a small but eclectic town.

This plant should be propagated by vegetative means only.
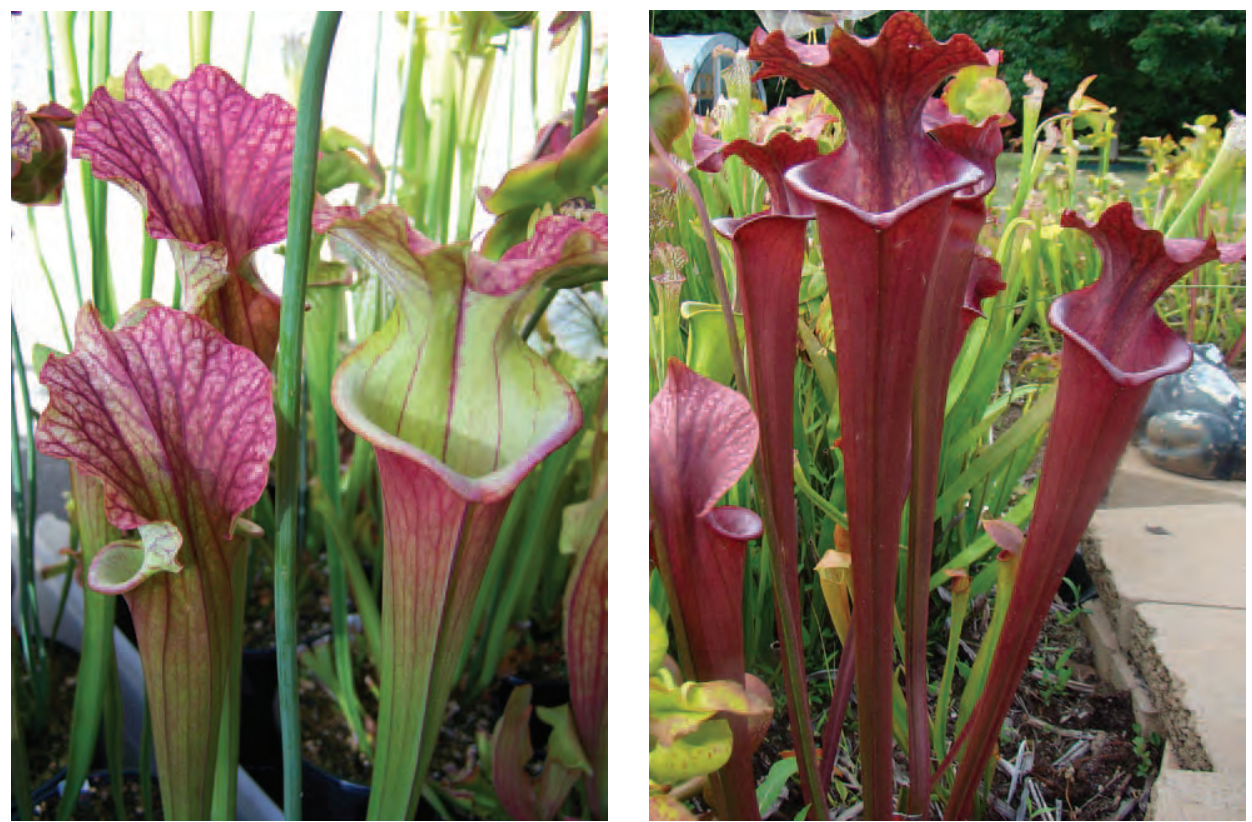

Figure 5: Sarracenia 'Saxapahaw' form and coloration in spring (left, photo by Fred Passkiewicz) and late summer (right, photo by Victor Holland).

- VICTOR HolLAND • 2125 B ordeaux D rive • M ebane • N orth Carolina $27302 \cdot$ USA • bogplants@ carnivorousplantpatch.com 